\title{
PERSEPSI SISWA DAN GURU TERHADAP PENGEMBANGAN MULTIMEDIA BERBASIS APLIKASI ANDROID
}

\author{
Abdul Haris Faisal ${ }^{1}$, Zuriyati ${ }^{2}$, Eva Leiliyanti ${ }^{3}$ \\ Universitas Negeri Jakarta ${ }^{1,2,3}$ \\ abdulharisf_s2@mahasiswa.unj.ac.id ${ }^{1}$ \\ Submit, 09-11-2019 Accepted, 27-12-2019 Publish, 27-12-2019
}

\begin{abstract}
ABSTRAK
Penelitian ini bertujuan untuk mengetahui persepsi siswa dan guru terhadap hasil pengembangan multimedia berbasis aplikasi android pada materi puisi untuk siswa SMA kelas X. Penelitian ini menggunakan metode kualitatif deskriptif. Hasil penelitian ini menunjukkan bahwa persepsi siswa terhadap pengembangan multimedia pembelajaran berbasis aplikasi pada materi puisi memperoleh rata-rata skor sebesar 3,82 dengan kategori layak. Adapun hasil penilaian guru mata pelajaran bahasa Indonesia memperoleh skor sebesar 4,23 dengan kategori sangat layak. Simpulan, penggunaan multimedia berbasis aplikasi andriod layak digunakan dalam kegiatan pembelajaran puisi
\end{abstract}

Kata Kunci: Persepsi, Multimedia, Berbasis Android

\section{ABSTRACT}

This study aims to determine students 'and teachers' perceptions of the results of developing android-based multimedia applications on poetry material for high school students in class X. This study uses descriptive qualitative methods. The results of this study indicate that students' perceptions of the development of application-based learning multimedia on poetry material obtained an average score of 3.82 with a decent category. The results of the assessment of Indonesian language teacher scores 4.23 in the very feasible category. Conclusion, the use of andriod-based multimedia applications is appropriate for use in poetry learning activities in high school.

Keywords: Perception, Multimedia, Android-based

\section{PENDAHULUAN}

Perkembangan teknologi sangat berpengaruh terhadap kemajuan dan perkembangan kualitas pendidikan. Salah satu hasil perkembangan teknologi yang pesat saat ini berupa penggunaan telepon pintar (smartphone) dengan sistem operasi android di semua lapisan masyarakat termasuk pelajar. Hal tersebut dianggap memiliki dampak yang baik dan positif untuk mendukung pihak sekolah dalam mengelola lembaga pendidikan, meningkatkan kualitas pembelajaran, dan meningkatkan keaktifan siswa dalam belajar (Falahudin, 2014). 
Penggunaan teknologi dalam pembelajaran dapat diintegrasikan melalui perangkat belajar berupa media. Media pembelajaran menjadi salah satu perangkat strategis yang dapat meningkatkan kualitas pembelajaran. Media pembelajaran memberikan pengalaman siswa untuk lebih mengeksplorasi dalam kegiatan pembelajaran (Leow \& Neo, 2014). Selain itu, penggunaan media pembelajaran memberikan kemudahan dalam memnyampaikan materi serta menanggulangi keterbatasan guru di dalam kelas. Menurut Calimag, et.al. (2014) penggunaan media berbasis android merupakan implementasi gaya belajar di abad 21. Penggunaan media berbasis android dapat meningkatkan efektifitas pembelajaran (Subiyantoro, 2018).

Pembelajaran puisi merupakan upaya untuk meningkatkan imajinasi siswa, meningkatkan kreativitas dan produktivitas peserta didik (Ismawati, Santosa, \& Ghofir, 2016; Satinem, 2018). Di samping itu, kegiatan belajar menulis puisi dilakukan dengan tujuan untuk meningkatkan kemampuan peserta didik dalam menuangkan realitas kehidupan yang ada dalam masyarakat melalui bahasa yang indah dan menarik. Kompetensi menulis puisi sesungguhnya bukan hanya bermanfaat untuk menunjang kemampuan berbahasa, akan tetapi bertujuan untuk menambah dan memperkaya wawasan serta kepribadian peserta didik.

Beberapa kendala yang dialami peserta didik diantaranya adalah: 1) ketidakmampuan peserta didik dalam menghasilkan ide atau gagasan untuk membuat sebuah puisi; 2) kegiatan pembelajaran menulis puisi kurang menarik minat peserta didik; 3) media pembelajaran yang digunakan kurang menarik peserta didik; dan 4) guru menjadi sumber dominan di kelas sehingga peserta didik lebih terfokus pada apa yang guru sampaikan (teacher center). Mendukung hasil pengamatan tersebut, Rahayu (2015) menyatakan bahwa pada saat pembelajaran menulis puisi, peserta didik merasa dihadapkan pada sebuah pekerjaan yang berat. Peserta didik merasa kesulitan dalam menuangkan gagasan atau ide ke dalam larik-larik puisi, kurang memiliki perbendaharaan kata yang memadai, kurang dapat memilih kata-kata dengan tepat serta kurang memahami bagaimana merangkai kata-kata ke dalam sebuah puisi.

Penelitian sebelumnya terkait persepsi terhadap media pembelajaran telah dilakukan di antaranya oleh Najichah, et.al (2018). Penelitian relevan lainnya dilakukan oleh Nugroho et.al (2017) melakukan penelitian mengenai persepsi siswa terhadap media pembelajaran berbasis blog pada mata pelajaran matematika. Penelitian- 
penelitian relevan sebelumnya lebih menekankan pada persepsi siswa terhadap pengembangan media buku dan blog dalam bidang sains. Sedangkan dalam penelitian ini berfokus pada bagaimana persepsi siswa dan guru terhadap hasil pengembangan multimedia pembelajaran berbasis aplikasi android untuk memahami materi puisi dan memudahkan siswa dalam menciptakan karya puisi yang kreatif.

Dalam upaya untuk meningkatkan kualitas kegiatan pembelajaran menulis puisi, guru harus mampu memanfaatkan potensi perkembangan teknologi yang sangat pesat agar mampu menciptakan sumber belajar yang menarik, mandiri, efektif, dan efisien. Hal tersebut sesuai dengan Peraturan Menteri Pendidikan dan Kebudayaan Republik Indonesia nomor 22 tahun 2016, untuk mewujudkan suasana dan proses pembelajaran yang interaktif, menyenangkan, memotivasi diri peserta didik dan turut aktif berpartisipasi, guru diharapkan dapat memanfaatkan berbagai sumber belajar agar potensi peserta didik dapat dikembangkan secara maksimal. Dukungan pemanfaatan teknologi dalam pembelajaran tidak hanya untuk memudahkan peserta didik dalam memahami materi pelajaran, lebih dari itu, penggunaan teknologi dapat mendorong peserta didik agar lebih aktif dan konrtibutif dalam proses pembelajaran.

\section{METODE PENELITIAN}

Metode dalam penelitian ini menggunakan metode deskripstif kualitatif dengan tujuan untuk mendeskripsikan persepsi siswa dan guru terhadap hasil pengembangan produk multimedia pembelajaran berbasis android pada materi puisi. Instrumen dalam penelitian ini menggunakan angket persepsi siswa dan guru. Sumber data penelitian ini adalah 30 siswa kelas X IPS 2 Madrasah Aliyah Negeri 2 Kabupaten Cirebon dan guru mata pelajaran bahasa Indonesia melalui penerapan multimedia pembelajaran berbasis aplikasi android. Selanjutnya, data yang diperoleh dianalisis menggunakan analisis data deskriptif dengan melakukan penjelasan data dan verifikasi data. Melalui teknik tersebut diperoleh hasil penelitian berupa persepsi siswa dan guru terhadap produk multimedia pembelajaran berbasis android pada materi puisi untuk siswa kelas X. Data yang diperoleh dari hasil angket siswa dan guru, selanjutnya dianalisis kemudian dikonversi ke dalam bentuk kualitatif dengan menggunakan skala Likert. 
Tabel 1

Konversi skor persepsi

\begin{tabular}{ccc}
\hline Interval Skor & Rentang & Kategori \\
\hline$\overline{\mathrm{X}}>X+1,80 \mathrm{Sbi}$ & $\mathrm{X}>4,20$ & Sangat Layak \\
\hline$\overline{\mathrm{X}}+0,60 \mathrm{SBi}<\mathrm{X} \leq \overline{\mathrm{X}}+0,60 \mathrm{Sbi}$ & $3,40<\mathrm{X} \leq 4,20$ & Layak \\
\hline$\overline{\mathrm{X}}-0,60 \mathrm{Sbi}<\mathrm{X} \leq \overline{\mathrm{X}}+0,60 \mathrm{Sbi}$ & $2,60<\mathrm{X} \leq 3,40$ & Cukup Layak \\
\hline$\overline{\mathrm{X}}-1,80 \mathrm{Sbi}<\mathrm{X} \leq \overline{\mathrm{X}}-0,60 \mathrm{Sbi}$ & $1,80<\mathrm{X} \leq 2,60$ & Kurang Layak \\
\hline $\mathrm{X} \leq \overline{\mathrm{X}}-1,80 \mathrm{Sbi}$ & $\mathrm{X} \leq 1,80$ & Sangat Kurang \\
\hline
\end{tabular}

\section{HASIL PENELITIAN}

Berikut adalah data hasil rekapitulasi persepsi siswa terhadap pengembangan produk multimedia pembelajaran berbasis android pada materi puisi

Tabel 2

Hasil Rekapitulasi Angket Persepsi Siswa

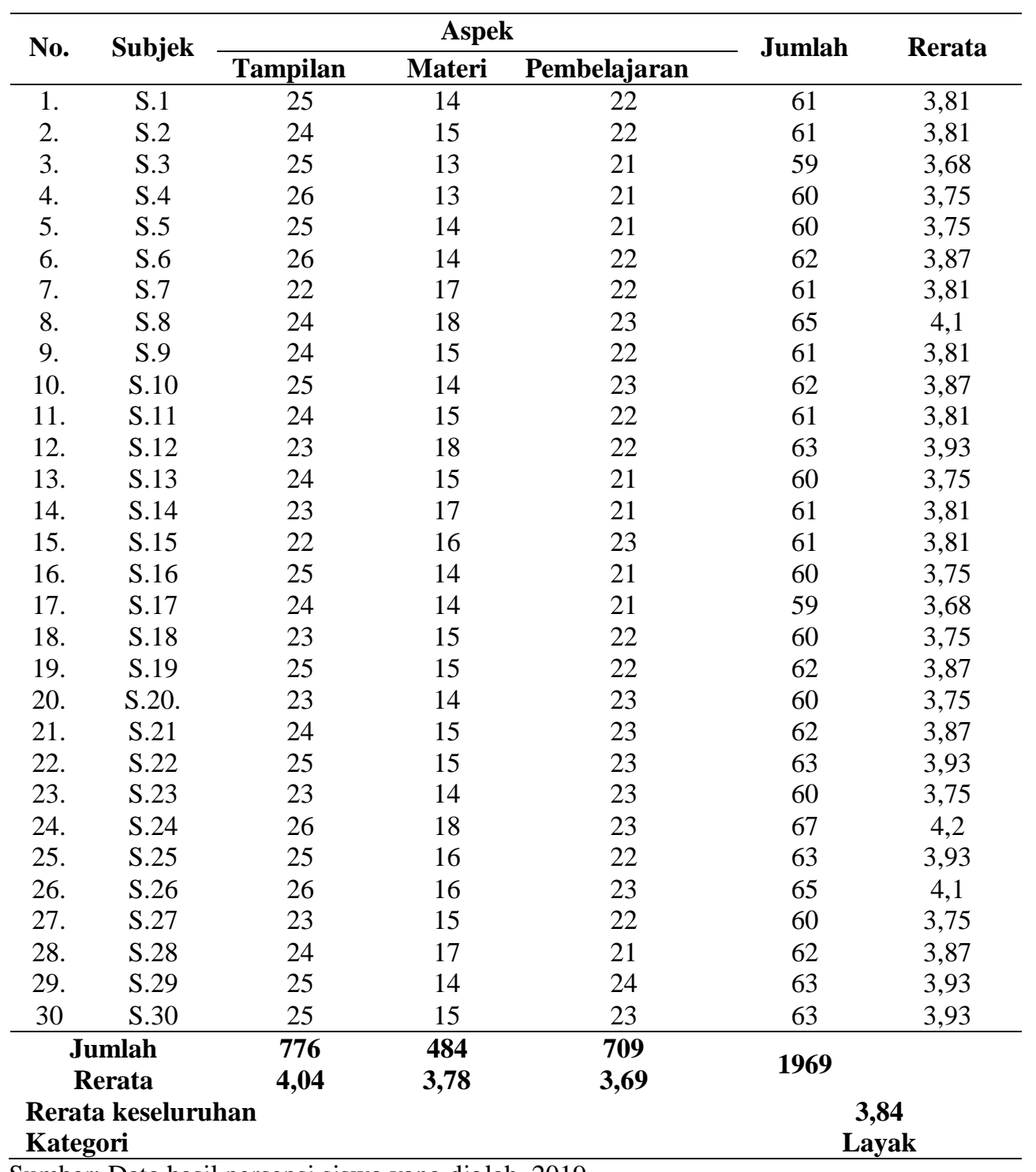

Sumber: Data hasil persepsi siswa yang diolah, 2019. 
Berdasarkan hasil rekapitulasi data dalam tabel persepsi siswa di atas, persepsi siswa terhadap pengembangan multimedia pembelajaran berbasis android pada materi puisi untuk siswa kelas $\mathrm{X}$ menunjukkan bahwa persepsi siswa terhadap aspek tampilan pada multimedia pembelajaran berbasis android memeroleh skor sebesar 4,04. Skor tersebut jika dikonversikan masuk dalam kategori layak. Pada aspek materi pada multimedia pembelajaran berbasis android memeroleh skor rerata sebesar 3,78. Skor hasil dari aspek materi jika dikonversikan termasuk dalam kategori layak. Adapun pasa aspek pembelajaran, mendapatkan kategori layak dengan memeroleh skor rerata sebesar 3,69. Berdasarkan hasil tersebut, rerata secara keseluruhan dari aspek tampilan, materi, dan pembelajaran sebesar 3,84. Berikut adalah data hasil rekapitulasi persepsi guru terhadap pengembangan multimedia pembelajaran berbasis android pada materi puisi.

Tabel 3

Hasil rekapitulasi angket persepsi guru

\begin{tabular}{lcccccc}
\hline \multirow{2}{*}{ Subjek } & \multicolumn{7}{c}{ Aspek } \\
\cline { 2 - 7 } & $\begin{array}{c}\text { Relevansi } \\
\text { KI \& KD }\end{array}$ & $\begin{array}{c}\text { Pengorganisasian } \\
\text { Materi }\end{array}$ & Bahasa & Isi Materi & Evaluasi & Tampilan \\
\hline \multicolumn{1}{c}{ G-1 } & 20 & 8 & 4 & 13 & 21 & 18 \\
G-2 & 22 & 8 & 5 & 12 & 22 & 17 \\
G-3 & 20 & 10 & 4 & 13 & 21 & 17 \\
\hline Jumlah & 62 & 25 & 13 & 38 & 64 & 52 \\
Rerata & 4,13 & 4,16 & 4,33 & 4,22 & 4,26 & 4,33 \\
Rerata & & & 4,23 & & &
\end{tabular}

Sumber: Data hasil persepsi guru yang diolah, 2019.

Berdasarkan rekapitulasi data dalam tabel persepsi guru di atas, persepsi guru terhadap pengembangan multimedia pembelajaran berbasis android pada materi puisi untuk siswa kelas X dapat dijelaskan dalam enam aspek. Aspek-aspek tersebut meliputi enam aspek, yaitu 1) aspek relevansi kompetensi inti dan kompetensi dasar; 2) aspek pengorganisasian materi; 3) aspek bahasa; 4) aspek isi materi; 5) aspek evaluasi; dan 6) aspek tampilan multimedia.

Pada aspek relevansi kompetensi inti dan kompetensi dasar mendapat skor rerata sebesar 4,13. Aspek pengorganisasian materi mendapatkan skor rerata sebesar 4,16. Aspek bahasa mendapatkan skor sebesar 4,33. Aspek isi materi mendapatkan skor rerata sebesar 4,22. Aspek evaluasi mendapatkan skor rerata sebesar 4,26. Pada aspek terakhir yaitu aspek tampilan multimedia mendapat skor rerata sebesar 4,33. 


\section{PEMBAHASAN}

\section{Persepsi Siswa}

Berdasarkan hasil rekapitulasi data di atas, persepsi siswa terhadap media pembelajaran menulis puisi berbasis android mendapatkan skor rerata keseluruhan sebesar 3,84 (X). Rerata keseluruhan tersebut terletak pada rentang $\mathrm{X} \leq 4,20$ yang berarti berada pada kategori layak. Kelayakan tampilan multimedia menjadi salah satu upaya untuk meningkatkan kualitas pembelajaran melalui visual yang menarik. Media visual seperti gambar dapat meningkatkan ketertarikan siswa dalam belajar. Penggunaan media gambar dengan tampilan yang menarik baik secara visual maupun audiovisual dapat mengatasi kesulitan siswa dalam belajar (Lazuardi \& Murti, 2018; Poniman, 2018).

Pada aspek tampilan mendapatkan skor tertinggi daripada dua aspek lainnya. Hal tersebut menunjukkan bahwa tampilan media secara visual mampu meningkatkan ketertarikan siswa dalam belajar. Persepsi siswa terhadap tampilan multimedia dinilai berdasarkan indikator yang terdiri dari kejelasan teks pada multimedia pembelajaran berbasis aplikasi android, kejelasan ikon tombol pada aplikasi, kemenarikan warna aplikasi, kesesuaian tampilan gambar, dan warna teks dan latar aplikasi.

Pada aspek materi dalam multimedia pembelajaran mendapat skor rerata sebesar 3,78 dengan kategori layak. Kelayakan tersebut dinilai berdasarkan indikator yang terdiri dari kejelasan pemaparan materi, kejelasan dalam penggunaan bahasa, materi mudah dipahami, serta tingkat kesulitan materi. Dari keempat indikator tersebut siswa menyatakan bawa aspek isi materi layak digunakan dalam pembelajaran.

Pada aspek ketiga yaitu aspek pembelajaran. Aspek tersebut merupakan aspek yang dinilai berdasarkan kegiatan pembelajaran dengan menggunakan multimedia berbasis aplikasi android. Aspek pembelajaran mendapat skor rerata terendah sebesar 3,69 meskipun masuk dalam kategori layak. Kelayakan tersebut dinilai dari 6 indikator yang meliputi media mendukung siswa untuk belajar secara mandiri, media menambah pengetahuan melalui kegiatan pembelajaran, kejelasan dalam setiap petunjuk pembelajaran, multimedia meningkatkan pemahaman, melakukan evaluasi pembelajaran, dan pemberian motivasi pembelajaran. 


\section{Persepsi Guru}

Pada aspek relevansi KI dan KD pada multimedia pembelajaran, memperoleh skor rerata sebesar 4,66 dengan kategori sangat layak. Penilaian kelayakan pada aspek ini terdiri dari 5 indikator yang meliputi kesesuaian kompetensi inti dan kompetensi dasar, kesesuaian tujuan pembelajaran dengan $\mathrm{KD}$, ketepatan materi pembelajaran dengan $\mathrm{KD}$, kesesuaian pemilihan materi puisi, dan kesesuaian materi dengan tujuan pembelajaran. Aspek relevansi KI dan KD bertujuan untuk menyelaraskan KI dan KD dengan tujuan serta materi pembelajaran sehingga pembelajaran dapat dicapai sesuai dengan tujuan pembelajaran.

Aspek relevansi KI dan $\mathrm{KD}$ didukung dengan aspek pengorganisasian materi yang terdiri dari kecakupan materi untuk mencapai kompetensi dasar dan kejelasan materi dalam menulis puisi. Berdasarkan dua indikator tersebut aspek pengorganisasian materi memperoleh skor rerata sebesar 4,13 yang masuk dalam kategori layak. Pengorganisasian materi disajikan melalui penggunaan bahasa yang baik dan benar sehingga untuk mendukung aspek tersebut dinilai juga melalui aspek penggunaan bahasa. Pada aspek peggunaan bahasa dinilai dengan indikator berupa kemudahan memahami materi melalui penggunaan bahasa. Kelayakan penggunaan bahasa memperoleh skor sebesar 4,33 yang masuk dalam kategori layak.

Persepsi guru terhadap aspek isi materi memperoleh skor rerata sebesar 4,22 dengan kategori sangat layak. Kelayakan aspek isi materi berdasarkan tiga indikator berupa kebenaran konsep materi puisi, keberagaman contoh puisi yang disajikan dalam multimedia, dan kejelasan dalam latihan analisis puisi. Selain itu, untuk menunjang pencapaian tujuan pembelajaran melalui multimedia berbasis aplikasi android terdapat penilaian terhadap aspek evaluasi atau latihan soal pada multimedia. Aspek evaluasi memperoleh skor rerata sebesar 4,26 dengan kategori sangat layak. Kelayakan evaluasi dinilai dari enam indikator berupa kejelasan instruksi dalam latihan menulis puisi, kejelasan petunjuk dalam pengerjaan latihan soal, relevansi soal dengan kompetensi, keberagaman jenis soal, dan tingkat kesukaran soal latihan.

Aspek terakhir yang penilaian guru terhadap multimedia berbasis android pada materi puisi adalah aspek tampilan visual multimedia. Aspek tampilan memperoleh skor sebesar 4,33 dengan kategori sangat layak. Pada aspek ini dinilai berdasarkan empat indikator berupa ketepatan tampilan teks dan gambar, kesesuaian pemilihan jenis huruf 
pada aplikasi, ketepatan pemilihan gambar, dan kemenarikan desain media. Berdasarkan keenam aspek di atas, maka persepsi guru terhadap multimedia berbasis aplikasi android pada materi puisi memperoleh skor rerata keseluruhan sebesar 4,23. Hal tersebut menunjukkan bahwa penilaian guru terhadap hasil pengembangan multimedia berbasis aplikasi android pada materi puisi layak untuk digunakan dalam kegiatan pembelajaran.

\section{SIMPULAN}

Persepsi siswa terhadap multimedia berbasis aplikasi android pada materi puisi dinilai dari aspek tampilan, aspek materi, dan aspek pembelajaran dalam kategori layak. Adapun persepsi guru terhadap pengembangan multimedia pembelajaran berbasis android pada materi puisi dinilai dari aspek relevansi kompetensi inti dan kompetensi dasar, aspek pengorganisasian materi, aspek bahasa, aspek isi materi, aspek evaluasi, dan aspek tampilan multimedia masuk dalam kategori sangat layak.

\section{DAFTAR PUSTAKA}

Calimag, J. N., Mugel, P. A., Conde, R. S., \& Aquino, L. B. (2014). Ubquitous learning environment using android mobile application. International Journal of Research in Engineering \& Technology , 2 (2), 119-128

Falahudin, I. (2014). Pemanfaatan Media dalam Pembelajaran. Jurnal Lingkar Widyaiswara, (4), 104-117.

Ismawati, E., Santosa, G. B., \& Ghofir, A. (2016). Pengembangan Model Pembelajaran Sastra Indonesia Berbasis Pendidikan karakter di SMA/SMK. Metasastra, 9(3), 185-200. https://doi.org/DOI: 10.26610/metasastra.2016.v9i2.185-200

Lazuardi, D. R., \& Murti, S. (2018). Peningkatan Kemampuan Menulis Puisi Menggunakan Model Pembelajaran Quantum Tipe VAK (Visual, Audiovisual, Kinestetik). Jurnal KiBASP (Kajian Bahasa, Sastra Dan Pengajaran), 2(1), 87-95. https://doi.org/10.1017/CBO9781107415324.004

Leow, F. T., \& Neo, M. (2014). Interactive multimedia learning: Innovating classroom education in a Malaysian university. Turkish Online Journal of Educational Technology, 13(2), 99-110. Retrieved from http://www.tojet.net/articles/v13i2/13211.pdf

Najichah, A. F., Nuryatin, A., \& Mulyani, M. (2018). Persepsi Pendidik dan Peserta Didik terhadap Pengembangan Buku Bacaan Cerita Fantasi Bermuatan Nilai Moral bagi Peserta Didik SMP Kelas VII. JP-BSI (Jurnal Pendidikan Bahasa dan Sastra Indonesia), 3(2), 58-65.

Nugroho, A. A., Putra, R. W. Y., Putra, F. G., \& Syazali, M. (2017). Pengembangan blog sebagai media pembelajaran matematika. Al-Jabar: Jurnal Pendidikan Matematika, 8(2), 197-203. 
Poniman. (2018). Upaya Meningkatkan Kemampuan Membaca Melalui Media Permainan Kartu Bergambar. Jurnal KIBASP (Kajian Bahasa, Sastra Dan Pengajaran), 2(1),

$48-58$. https://doi.org/https://doi.org/10.31539/kibasp.v2i1.441

Rahayu, S. (2015). Peningkatan Motivasi dan Keterampilan Menulis Puisi dengan Media Gambar pada Siswa Menengah Pertama. Kajian Linguistik Dan Sastra, 27(2), 126-133. https://doi.org/https://doi.org/10.23917/kls.v27i2.4481

Satinem, J. (2018). Development of Teaching Materials of Poetry Writing Using Pictures for the Elementary Students. AIAC, 9(3). Retrieved from http://journals.aiac.org.au/index.php/alls/index

Subiyantoro, S. (2018). Android-based Instructional Media Development Procedure to Enhance Teaching and Learning in The Age of Disruption 4 . 0. In International Conference on Applied Science and Engineering (ICASE 2018) (Vol. 175, pp. 152-155). Atlantis Press. https://doi.org/https://dx.doi.org/10.2991/icase-18.2018.41 